\title{
Effects of Ultrasound Therapy on Balance and Gait in Stroke Patients with Gastrocnemius Muscle Spasticity
}

\author{
Yun-Ho Choi, Young-Han Park*, Sang-Hyuck Park
}

\begin{abstract}
The purpose of this study is to investigate the effect of ultrasound therapy on calf muscle spasticity of stroke patients. Ten patients who were diagnosed with stroke by a specialist in rehabilitation medicine were divided into two groups by random assignment method. The control group received a 10-minute ultrasound placebo effect after general physiotherapy. In the experimental group, ultrasound therapy was given for 10 minutes after general physical therapy. In this study, muscle tone was assessed using MAS(modified ashworth scale), balance was assessed using TUG(time up \& go), and gait was assessed using a $10 \mathrm{~m}$ walk test. There was a significant difference between the experimental group and the muscle tone, balance, and gait. However, there was no significant difference in the control group. There was a significant difference between the groups in balance and gait, but not in muscle tone. Ultrasound therapy should be adapted to reduce spasticity and improve function in stroke patients.
\end{abstract}

Index Terms - Ultrasound therapy, Stroke, Spasticity, Balance, Gait

\section{INTRODUCTION}

According to Statistics Korea(2011)[1], cerebrovascular disease is one of the three major causes of deaths in Korea, along with malignant neoplasms and heart disease, with an incidence of 48.6 per 100,000 men and 52.8 per 100,000 women. In most Western countries and the U.S., strokes are the third leading cause of death and the most important cause of chronic disability [2].

A stroke is a neurological disorder that causes local brain tissue abnormalities and dysfunction due to an insufficient supply of oxygen and glucose to the brain tissues for a continuous period [3]. The latter results in decreased blood supply to the brain and cerebrovascular injury due to brain ischemia or hemorrhages. Stroke-induced functional changes are manifested differently, depending on the type and degree of brain damage, and they include muscle paralysis, speech disturbances, alterations in behavior and thinking patterns, and changes in memory and emotions[4]. These problems lead to limitations of a number of activities and a reduced range of motion, resulting in secondary problems, such as

Yun-Ho Choi, Department of Physical Therapy, Korea National University of Transportation, Jeungpyeong-gun, Republic of Korea

Young-Han Park*(corresponding author), Department of Physical Therapy, Korea National University of Transportation, Jeungpyeong-gun, Republic of Korea

Sang-Hyuck Park, Department of Physical Therapy, Korea National University of Transportation, Jeungpyeong-gun, Republic of Korea muscle weakness, reduced joint motion range, shortening of muscle fibers related to spasticity, contracture, and changes in alignment, which ultimately decrease the patient's motor control ability[5].

Spasticity is a component of upper motor neuron syndrome, which is a motor disorder characterized both by excessive tendon reflexes caused by hyper-excitability of the stretch reflex and by an increased tonic stretch reflex in proportion to the speed of movement[6]. Spasticity occurs in the flexor muscles of the upper limbs and in the extensor of the lower limbs, and it can result in a limited range of joint motion due to the contracture of the involved joints and antalgic gait disturbance[7]. Increased muscle tension and resistance to passive movement caused by spasticity may be associated with various problems. such as balance disturbances, impairment of hand function control, sleep disturbances due to flexor spasms and myoclonus, sexual dysfunction, difficulty in managing catheters, speech disturbances, and joint mobility dysfunction[8].

Stroke patients have reduced balance ability due to their inability to maintain the center of gravity within the body's limit of stability. Stroke-related reductions in balance ability can interfere with motor recovery, make it difficult to return to daily life, and increase the risk of falls[9]. Reducing muscle spasticity in patients with spastic hemiplegia may lead to improved standing balance control[10].

Spasticity of ankle joints caused by strokes also affects the patient's gait. In a normal gait, dorsiflexion of about $10^{\circ}$ is required for the ankle joint, which accounts for $80 \%$ of the gait cycle[11]. The gait patterns of stroke patients show a delayed swing phase due to dysfunction of the paralyzed lower limb, a reduced stance phase, and insufficient body center movement[12]. Therefore, to improve the balance and gait ability of stroke patients, therapeutic interventions that can reduce spasticity of the gastrocnemius muscle and thereby induce smooth movement of the ankle joint are needed.

Current treatments for spasticity include exercise therapy, pharmacotherapy, chemical nerve block, and motor point block, but full recovery is not possible[13]. For surgical therapy, selective dorsal rhizotomy that can reduce the intensity of afferent stimulation is available. Pharmacotherapy includes intrathecal baclofen injections and botulinum toxin injections. Pharmacotherapy is easy to apply and effective. However, the efficacy of the drug is relatively short, and long-term repeated dosing may result in tolerance to the drug[14]. In terms of other intervention methods, 
electrotherapy devices used in physical therapies have been applied recently, and they have been found to be safe, easy, and tolerance resistant[15].

Functional electrical stimulation, which is one technique to reduce spasticity, causes muscles to contract/stretch regularly, while the stimulus decreases showing a centripetal tendency[16]. Another technique uses extracorporeal shock wave devices. One study reported that 1,000 shots of extracorporeal shock wave therapy for 4 weeks slightly decreased spasticity in elbow flexion and wrist pronator teres[17]. Ultrasound therapy has been recommended for tissue recovery because it increases tissue elasticity and flexibility, thereby promoting wound healing and collagen relaxation[18]. The increase in tissue temperature induced by ultrasound causes relaxation of collagen tissues by changing the mucosal elasticity of collagen and causing plastic deformation[19]. Several authors reported that ultrasound therapy resulted in relaxation of stiff muscles locally and increased extensibility of tendons and muscles[20][21]. However, the applicability of ultrasound therapy to spasticity has not been established. Therefore, this study aimed to investigate the effects of ultrasound therapy on balance and gait in stroke patients with gastrocnemius muscle spasticity.

\section{STUDY METHOD}

\section{A. Subjects}

Patients who were diagnosed with a stroke and hospitalized at a rehabilitation hospital were divided into a control group $(n=10)$ and an experimental group $(n=5)$ by the random assignment method. The selection criteria for inclusion in the study were as follows: patients older than 65 years who had a stroke more than 6 months earlier; patients with a Modified Ashworth Scale (MAS) grade of 1-2; patients who could walk more than $14 \mathrm{~m}$ independently, regardless of the use of walking aids; patients with a Korean Mini-Mental Statue Examination score of 24 or more who could understand and comply with the investigator's instructions; and patients who were not participating in regular exercise or other exercise programs. The exclusion criteria were as follows: patients with ankle contracture or deformities, patients unable to perform tasks due to cognitive decline, patients with additional neurological diseases, or patients who had received surgery on the paralyzed ankle joint. Before the start of the study, the purpose and method of the study were explained in detail to the patients. Prior to the experiment, all the patients volunteered to take part in the study and provided written informed consent, and the study was conducted in accordance with the ethical standards of the Helsinki Declaration.

\section{B. Treatment}

Both groups received $30 \mathrm{~min}$ of proprioceptive neuromuscular facilitation therapy, which is a general physical therapy. Thereafter, the patients in the control group received placebo ultrasound therapy for $10 \mathrm{~min}$, followed by $10 \mathrm{~min}$ of ankle stretching. The patients in the experimental group received $10 \mathrm{~min}$ of ultrasound therapy, followed by ankle stretching for and $10 \mathrm{~min}$. The patients received the therapy three times a week for 4 weeks (12 sessions in total).
In the study, the patients in the experimental group adopted a comfortable prone position on a treatment bed. The site for ultrasound application was then exposed, and ultrasound was applied to the medial head of the gastrocnemius muscle for 10 $\min$ at $1 \mathrm{MHz}, 2 \mathrm{~W} / \mathrm{cm}^{2}$ along the direction of the muscle fibers. During the application, a towel was placed under the patient's ankle to minimize gastrocnemius muscle tension. The same method was applied in the control group, but the ultrasound device was not turned on (placebo effect).

\section{Assessment}

The MAS was used to assess muscle tension. The MAS consists of six levels, which are divided into 0 to 4 grades, but in this study the score was expressed as 1-6 points for evaluation[22]. The Time Up \& Go (TUG) test was used to evaluate balance. The TUG, which measures the time spent to complete a task, is an appropriate tool for assessing balance, mobility, and functional mobility[23]. A 10-m walk test was used to evaluate gait. In this test, which has been validated previously[24]. the time taken to walk a 10-m walking section of a 14-m walking path, excluding the 2-m section of the accelerating phase and 2-m section of the decelerating phase, was measured. The patients' performances before and after the 4-week intervention were measured.

\section{Data analysis}

In this study, SPSS (version 22.0) was used for data processing. The Shapiro-Wilk test was used to examine whether the variables showed a normal distribution pattern. An independent $t$-test was performed to test the prehomogeneity of the dependent variables in each group. A paired $t$-test was performed to compare changes in muscle tension, balance, and dependent gait variables within the groups, and an independent $t$-test was performed to compare differences between the groups. In all the tests, statistical significance was accepted at $p<.05$. Data was analyzed using SPSS 20.0 for Windows. Paired t-tests were used to compare differences in pain and balance for before and after the experiment and independent t-tests were used to compare differences in pain and balance between groups. All data values were indicated as mean \pm standard deviation and the significance level was set to $\alpha<0.05$.

\section{RESULTS}

A homogeneity test was performed to determine the relati onship of the dependent variables before the intervention bet ween the experimental group and the control group. There we re no statistically significant differences in any of the variabl es in each group for MAS, TUG, and 10-m walk $(p>.05)(\mathrm{T}$ able 1). Within-group statistically significant differences in MAS scores were detected in the experimental group $(p<.05$ ), but not in the control group (Table 2). There were also no $s$ ignificant between-group differences in MAS scores $(p>.05)$ (Table 3). There was a statistically significant difference in $\mathrm{t}$ he TUG test in the experimental group $(p<.05)$, but no signi ficant difference in the TUG test was found in the control gro up $(p>.05)$ (Table 4). There was a significant between-grou $\mathrm{p}$ difference in the TUG test $(p<.05)$ (Table 5). The results of the 10-m walk also revealed a statistically significant diffe 
rence in the experimental group $(p<.05)$, but no significant difference was found in the control group $(p>.05)$ (Table 6). There was a significant between-group difference in the 10m walk $(p<.05)$ (Table 7).

Table 1. Results of prehomogeneity test for dependent variables

\begin{tabular}{ccccc}
\hline & $\begin{array}{c}\text { Control } \\
\text { group } \\
(\mathrm{n}=5)\end{array}$ & $\begin{array}{c}\text { Experimenta } \\
\text { 1 group } \\
(\mathrm{n}=5)\end{array}$ & $t$ & $p$ \\
\hline MAS & $3.00 \pm 0.70$ & $3.20 \pm 0.83$ & 0.408 & 0.694 \\
TUG & $41.87 \pm 1.43$ & $44.96 \pm 4.14$ & 1.572 & 0.177 \\
$\begin{array}{l}10-\mathrm{m} \\
\text { walk }\end{array}$ & $60.09 \pm 4.22$ & $62.91 \pm 6.50$ & 0.821 & 0.436 \\
\hline MAS, Modified Ashworth scale; TUG, Time Up \& Go
\end{tabular}

Table 2. Comparison of MAS between groups.

\begin{tabular}{ccccc}
\hline & $\begin{array}{c}\text { Control } \\
\text { group } \\
(\mathrm{n}=5)\end{array}$ & $\begin{array}{c}\text { Experimental } \\
\text { group } \\
(\mathrm{n}=5)\end{array}$ & $t$ & $p$ \\
\hline Pre-test & $3.00 \pm 0.70$ & $3.20 \pm 0.83$ & & \\
Post-test & $2.80 \pm 0.44$ & $2.40 \pm 0.54$ & -2.121 & 0.067 \\
$t$ & 1.000 & 4.000 & & \\
$p$ & 0.374 & $0.016^{*}$ & & \\
\hline${ }^{*} p<0.05$ & & & &
\end{tabular}

Table 3. Comparison of TUG between groups.

\begin{tabular}{ccccc}
\hline & $\begin{array}{c}\text { Control } \\
\text { group } \\
(\mathrm{n}=5)\end{array}$ & $\begin{array}{c}\text { Experimental } \\
\text { group } \\
(\mathrm{n}=5)\end{array}$ & $t$ & $p$ \\
\hline Pre-test & $41.87 \pm 1.43$ & $44.96 \pm 4.14$ & & \\
Post-test & $38.57 \pm 5.32$ & $35.61 \pm 1.76$ & & \\
$t$ & 1.768 & 6.283 & $0.035^{*}$ \\
$p$ & 0.152 & $0.003^{*}$ & & \\
\hline${ }^{*} p<0.05$ & & & &
\end{tabular}

Table 4. Comparison of 10-m walk between groups.

\begin{tabular}{ccccc}
\hline & $\begin{array}{c}\text { Control } \\
\text { group } \\
(\mathrm{n}=5)\end{array}$ & $\begin{array}{c}\text { Experimental } \\
\text { group } \\
(\mathrm{n}=5)\end{array}$ & $t$ & $p$ \\
\hline Pre-test & $60.09 \pm 4.22$ & $62.91 \pm 6.50$ & & \\
Post-test & $59.09 \pm 4.15$ & $53.42 \pm 7.23$ & -2.703 & $0.048^{*}$ \\
$t$ & 0.302 & 9.090 & & \\
$p$ & 0.778 & $0.001^{*}$ & & \\
\hline${ }^{*} p<0.05$ & & & &
\end{tabular}

\section{DISCUSSION}

When spasticity persists in stroke patients, secondary problems tend to ensue. These problems include reduced movements in the hemiplegic side, changed gate patterns due to abnormal weight support, reduced muscular contraction abilities, and alterations in the characteristics of the connective tissues of the paralyzed lower limbs[25].

Spasticity is particularly common in the ankle joint, which is one of the most important joints for balance and gait. Lack of motor ability in the ankle hampers balance and gait ability, which makes the ankle strategy unusable and increases the risk of falls[26]. Therefore, to improve balance and gait functions of stroke patients, secondary problems caused by gastrocnemius muscle spasticity must be treated, with the treatment focusing on enabling the ankle strategy.

Ultrasound is a safe, noninvasive method that penetrates deep into the muscles and causes micro vibrations, which generate heat. The generated heat relaxes connective tissues and fascia of the muscles, thereby restoring the flexibility of the deep tissues and ensuring joint mobility. Markert et al. (2005)[27] reported that using an ultrasound device could increase the extensibility of collagen fibers, thereby restoring the range of joint motion.

As the range of motion of the ankle joint is improved, the ankle strategy can be used efficiently, which can in turn affect balance. Son(2005)[28] investigated the effect of ankle-strengthening exercises and ankle-stretching exercises on balance control ability and reported statistically significant improvements. Lee(2015)[29] showed that ankle joint mobility significantly increased following the application of ultrasound and static extension to the ankle joints of 20 stroke patients, which was consistent with the results of the present study.

In the human body, the ankle joint absorbs shock from the ground during walking and provides propulsive force to move forward[30]. In a study by Kim et al.(2007)[31], functional electrostatic stimulation and ankle-strengthening exercises applied to 20 stroke patients resulted in statistically significant improvements in their balance and gait ability.

Based on the above results, we hypothesized that the application of ultrasound therapy to stroke patients with gastrocnemius muscle spasticity would enhance the flexibility of the ankle joint, thereby enabling the ankle strategy and improving balance and gait ability. According to the findings of the present study, the ultrasound therapy applied in this study did not result in any statistically significant difference in muscle tension between the groups. However, statistically significant decreases in muscle tension were observed in the experimental group after the intervention. Although balance decreased in the control group after the intervention, the decrease was not statistically significant, and the differences in balance within the experimental group and between the groups statistically significantly decreased. There was no difference in gait ability in the control group, and the differences in gait ability within the experimental group and between the groups statistically significantly decreased.

These results suggest that ultrasound therapy combined with physical therapies used to treat spasticity can reduce spasticity of the ankle joint, thereby improving ankle joint mobilization and enabling the ankle strategy. The resulting improvement of balance and gait ability in stroke patients is expected to help them to restore their daily living ability and quality of life.

The limitations of the present study were as follows: First, the sample size was very small, and second, the duration of 
treatment was very short. For these reasons, it may be difficult to generalize the results of the present study. However, this study can pave the way for active research on the application of ultrasound therapy for spasticity.

\section{ACKNOWLEDGMENT}

This study was supported by Korea National University of Transportation 2018.

\section{REFERENCES}

[1] National Statistical Office, "Cause of death in 2011," 2012.

[2] Feigin VL, Rinkel GJ, Lawes CM, Algra A, Bennett DA, van Gijn J, Anderson CS, "Risk factors for subarachnoid hemorrhage: an updated systematic review of epidemiological studies. Stroke," 12 vol. 36, 2005, pp. 2773-2780.

[3] O' Sullivan S. B., Thomas J.\& Schmitz, "Physical Rehabilitation: Assessment and Treatment $\left(4^{\text {th }}\right.$ ed)", Philadelphia: F. A. Davis Co. 2001.

[4] Burridge Jh, Wood DE, Taylor PN et al, "Indices to describe different muscle activation patterns, identified during treadmill walking, in people with spastic drop-foot," 6 vol. 23, Med Eng Phy, pp. 427-434.

[5] Shumway-Cook A, woollacott MH, "Motor Control: Translating research into clinical practice $\left(3^{\text {rd }}\right.$ ed $)$, , Philadelphia: Lippincott Wiliams \& Wilkins, 2007.

[6] Kim JM, "Neuroanatomy \& Neurophysiology," jeoungdam, 2000, pp. 310-311.

[7] Welmer AK, Holmqvist LW, Sommerfeld DK, "Hemiplegic limbsynergies in stroke patients," Am J Phys Med Rehabil, 2 vol. 85 2006, pp.112-119.

[8] Middleton JW, Siddall PJ, Walker S et al, "The Effects of Handrails during Treadmill Gait Training in Stroke Patients," 1 vol. 25, J Korean Soc Phys Ther, 1996, pp. 25-28.

[9] Tyson SF, Hanley M., Chillala J., Selley A. \& Tallis R. C., "Balance disability after stroke," 1 vol. 86, Physical therapy, 2006, pp. 30.

[10] Cakar E., Durmus O., Tekin L., Dincer U., Kiralp M. Z., "The ankle-foot orthosis improves balance and reduces fall risk of chronic spastic hemiparetic patients," 3 vol. 46, Eur. J. Phys. Rehabil. Med, 2010, pp. 363-368.

[11] Jung SI, Oh SH, Kim JO, Park KH, "Reaction of Ankle Muscles by Functional Electrical Stimulation," 1 vol. 22, Transactions of the Korean Society for Noise and Vibration Engineering, 2012, pp. 15-21.

[12] Olney SJ, and Richard CL, "Hemiparetic gait following stroke, part I : Characteristics," vol. 4, Gait Posture, 1996, pp. 136-148.

[13] Satkunam LE, "Rehabilitation medicine: 3. Management of adult spasticity," 11 vol. 169, CMAJ, 2003, pp.1173-1179.

[14] Shakespeare DT, Young CA, Boggild M, "Anti-spasticity agents for multiple sclerosis," Cochrane Database Syst Rev. 4:CD001332, 2000.

[15] Kim BY, "The Effects of Interferential Current Therapy to Gastrocnemius on Spasticity, Range of Motion, and Balance Ability in Patient with Stroke," Department of Physical Therapy Graduate School of Public Health Gachon University, 2013.

[16] Park KH, Kim SK, Chung HA, Park, RJ, "The Review of Functional Electrical Stimulation," 2 Vol. 13, The Journal of Korean Society of Physical Therapy, 2001, pp. 299-405.

[17] Yoo SD, Kim HS, Jung PK, "The effect of shock wave therapy on upper limb spasticity in the patients with stroke," vol. 32, J Korean Acad Rehab Med, 2008, pp. 406-410.

[18] Starkey C, "Therapeautic Modalities (2nd ed)," philadelphia, FA. Davis, 1993, pp. 110-29.

[19] Lehmann JF, Lateur BJ, "Diathermy and superficial heat and cold therapy. InKrusen's Handbook of physical medicine and rehabilitation. Kottke FJ, Lehmann JF 4thed," philadelphia:WB Saunders, 1990.

[20] Giebler K. B.: Physical modalities. In: Glenn M. B., Whyte, J.(Ed), "The physical management of spasticity in children and adult," Lea \& Febiger, Philadelphia, 1990, pp. 118-148.

[21] Wessling K. C., Devane D. A., Hylton C. R., "Effect of static stretch versus static stretch and ultrasound combined on triceps surae muscle extensibility in healthy women," 5 vol. 67, Physical Therapy, 1987, pp. 674.

[22] Wallen MA, O'flaherty SJ, Waugh MC, "Functional outcomes of intramuscular botulinum toxin type $\mathrm{A}$ in the upper limbs of children with cerebral palsy: a phase II trail," 2 vol. 85, Arch Phys Med Rehabil, 2004, pp. 192-200.
[23] Morris S, Morris ME, Iansek R, "Reliability of measurements obtained with the timed up and go testin people with Parkinson disease," 2 vol. 82, PhysTher, 2001, pp.810-818.

[24] Van Loo, M. A., Moseley, A. M., Bosman, J. M., De Bie, R. A., Hassett, L., "Test-.re-test reliability of walking speed, step length and step width measurement after traumatic brain injury: a pilot study," 18 vol. 10, Brain Injury, 2004, pp. 1041-1048.

[25] Kim BY, Kim TM, Che JM, Jo KH, "The kinematic characteristics observed during the onset of walking in patients with stroke," 2 vol. 25 , Annals of Rehabilitation Medicine, 2001, pp. 227-235.

[26] Lamontagne, A., Malouin, F., Richards, C. L., \& Dumas, F, "Mechanisms of disturbed motor control in ankle weakness during gait after stroke," 3 vol. 15, Gait Posture, 2002, pp. 244-255.

[27] Markert CD, Merrick MA, Kirby TE, Deyor ST, "Nonthermal ultrasound and exercise in skeletal muscle regeneration" vol. 86, Arch Phys Med Rehabil, pp. 1304-1310.

[28] Son JC, "The Effects of Ankle Strength Exercise on the Ability of Balance Control in Patients with Stroke," Department of Physical Therapy Graduate School of Rehabilitation Health Science Yong In University, 2005.

[29] Lee SH, "The Effects of Therapeutic Ultrasound with Static Stretching on Gastrocnemius Muscle on Range of Motion and Balance of Stroke Patients," Department of Physical Therapy Graduate School of Health and Medical Science, Catholic University of Daegu, 2015.

[30] Donald AN, "Kinesiology of the Musculoskeletal System: Founsations for Physical Rehabilitation," Mosby Publication, 2002, pp. 528-529.

[31] Kim Bj, Lee SK, Kim MK ,"The Effects of Ankle Strength Exercise and Functional Electrical Stimulation on the Ability of Balance Control and Gait in Stroke Patients," Journal of Sport and Leisure Studies 31, 2007, pp. 921-931

Yun-Ho Choi, He is currently a physical therapist in Korea. His research interests are stroke, neurological lesion rehabilitation and PNF. Currently, he is in the master's course at the Korea National University of Transportation.

Young-Han Park, he received $\mathrm{PhD}$ degree from Daegu University, Republic of Korea. His research interests include Electrical therapy, Phototherapy, Neurophysiology, Neuroanatomy, and Sports Physiotherapy. He had completed a lot of training in orthopedic and neurological Sciences Institute. He is currently working as Professor of Department of Physical Therapy, Korea National University of Transportation, Republic of Korea.

Sang-Hyuck Park, He is currently a physical therapist in Korea. His research interests include Rehabilitation, Osteoarthritis, Shoulder Disorders, and Taping. He had completed a lot of training in orthopedic and neurological Sciences Institute. He graduated from Korea National University of Transportation. 